\title{
Adjunctive use of systematic retinal thickness map analysis to monitor disease activity in punctate inner choroidopathy
}

\author{
Savitha Madhusudhan ${ }^{1,2}$, Pearse A. Keane ${ }^{3}$ and Alastair K. Denniston ${ }^{1,2,4^{*}}$ (D)
}

\begin{abstract}
A challenge in the management of 'white dot syndromes' is the lack of sensitive objective measures of disease activity. Retinal thickness maps from spectral domain optical coherence tomography (SD-OCT) inform treatment decisions in other retinal conditions such as age-related macular degeneration and diabetic maculopathy. In this report, we demonstrate their value in providing quantitative monitoring of a patient with punctate inner choroidopathy (PIC). Retinal thickness maps referenced against a baseline scan reliably detected focal areas of increased macular volume in active PIC lesions during symptomatic episodes, highlighting these as 'hot spots' that could be quantified, providing an objective basis for treatment decisions.
\end{abstract}

Keywords: Punctate inner choroidopathy, Retinal thickness map, White dot syndromes, SD-OCT, Macular grid

\section{Findings}

\section{Introduction}

Punctate inner choroidopathy (PIC) is a rare idiopathic inflammatory condition affecting the outer retina, retinal pigment epithelium and choroid that mostly occurs in young myopic females and predominantly affects the posterior pole [1]. It runs a variable course, with multiple recurrences in up to a third of patients and can be associated with severe visual loss when complicated by choroidal neovascularisation (CNV) and subretinal fibrosis [2]. Stages in the evolution of PIC lesions on spectral domain optical coherence tomography (SD-OCT) have been described $[3,4]$. Although blue wavelength fundus autofluorescence (FAF) can help discriminate between active and atrophic lesions, findings can sometimes be ambiguous [5]. We describe the application of systematic retinal thickness map analysis of SD-OCT (Heidelberg Eye Explorer ${ }^{\mathrm{Tw}}$, Heidelberg, Germany) as a useful adjunct in detecting lesion activity in PIC.

\footnotetext{
* Correspondence: a.denniston@bham.ac.uk

${ }^{1}$ Centre for Rare Diseases, University Hospitals Birmingham NHS Foundation Trust, Birmingham, UK

${ }^{2}$ Ophthalmology Department, University Hospitals Birmingham NHS

Foundation Trust, Birmingham, UK

Full list of author information is available at the end of the article
}

\section{Case example}

A 43-year-old Caucasian female was diagnosed with PIC after presenting with photopsia associated with active retinal lesions and multifocal chorioretinal atrophic lesions in the macula in her left eye. Her right eye had long-standing macular scarring with vision of 'hand movements'. Oral corticosteroid treatment for her active PIC lesions resulted in visual acuity improving from 6/ 12 to $6 / 6$ in the left eye. It was noted that although treatment response was not easily determined on nonquantitative assessment of the SD-OCT images, reduction in lesion size could easily be detected and objectively measured using retinal thickness maps (Heyex $\left.{ }^{\mathrm{Tm}}\right)$.

Recurrent exacerbations of the disease resulted in increasing maintenance treatment (mycophenolate mofetil $1 \mathrm{~g}$ bid; oral prednisolone $10 \mathrm{mg}$ od) with individual flares being treated with intravitreal corticosteroid; a choroidal neovascular membrane was treated with a course of intravitreal bevacizumab injections. Retinal thickness maps based on automated segmentation lines delineating internal limiting membrane and Bruch's membrane proved consistently reliable, showing focal retinal thickening in the form of 'hot spots' at sites which were suspicious for new activity on SD-OCT (Table 1). Following intravitreal steroid treatment, the 
Table 1 Outcomes of methods used to detect active PIC lesions in the patient's left eye

\begin{tabular}{|c|c|c|c|c|c|c|c|}
\hline $\begin{array}{l}\text { Symptom } \\
\text { episodes }\end{array}$ & $\begin{array}{l}\text { Unaided Snellen visual } \\
\text { acuity (pinhole } \\
\text { vision when tested) }\end{array}$ & $\begin{array}{l}\text { Clinically } \\
\text { identifiable } \\
\text { lesion }\end{array}$ & $\begin{array}{l}\text { New changes } \\
\text { in FAF }\end{array}$ & $\begin{array}{l}\text { New changes } \\
\text { in SD-OCT }\end{array}$ & $\begin{array}{l}\text { 'Hot spots' on } \\
\text { thickness map }\end{array}$ & $\begin{array}{l}\text { Maximal increase in } \\
\text { thickness within a 'hot spot' } \\
\text { compared to immediate } \\
\text { previous visit }(\mu \mathrm{m})\end{array}$ & Treatment \\
\hline $\begin{array}{l}1 \text { December } \\
2014\end{array}$ & $6 / 6$ & No & No & Yes & Yes & 56 & IVTA \\
\hline 27 January 2015 & $6 / 7.5$ & Yes & No & Yes & Yes & 102 & IVTA \\
\hline 13 March 2015 & $6 / 9(6 / 6)$ & Doubtful & $\begin{array}{l}\text { FAF } \\
\text { unavailable }\end{array}$ & Yes & Yes & 103 & IVTA \\
\hline 12 May 2015 & $6 / 6$ & No & No & Yes & Yes & 12 & $\begin{array}{l}\text { Intravitreal } \\
\text { dexamethasone } \\
\text { implant }\end{array}$ \\
\hline 11 August 2015 & $6 / 9$ & No & $\begin{array}{l}\text { FAF } \\
\text { unavailable }\end{array}$ & Yes & Yes & 21 & IVTA \\
\hline $\begin{array}{l}29 \text { September } \\
2015\end{array}$ & $6 / 9$ & No & Doubtful & Yes & Yes & 67 & $\begin{array}{l}\text { Intravitreal } \\
\text { dexamethasone } \\
\text { implant }\end{array}$ \\
\hline
\end{tabular}

FAF fundus autofluorescence, IVTA intravitreal triamcinolone

thickness map returned towards baseline each time, corresponding with the resolution of symptoms (Fig. 1).

These maps also enabled an estimation of what constituted a 'symptomatic' deterioration. Comparing each 'active' episode to the preceding 'quiescent' visit showed that the mean detectable change of retinal thickness associated with symptoms was $60.2 \mu \mathrm{m}$ (range 12-103 $\mu \mathrm{m}$ ). The average increase in retinal thickness during a flare in the inner $(1 \mathrm{~mm})$, middle $(3 \mathrm{~mm})$ and outer $(6 \mathrm{~mm})$ zones of the ETDRS macular grid was $18.2 \mu \mathrm{m}$ (range 10-33 $\mu \mathrm{m}$ ), $25.9 \mu \mathrm{m}$ (range 3-59 $\mu \mathrm{m}$ ) and $12.6 \mu \mathrm{m}$ (range 14-28 $\mu \mathrm{m}$ ), respectively, with more hot spots recurring in the middle, inner and outer zones in that order (Table 1). This patient has given specific consent for her clinical data and images to be published.

\section{Discussion}

A major challenge in managing patients with 'white dot syndromes' is the lack of sensitive measures of disease activity that can provide objective guidance for treatment decisions. This is particularly important when dealing with sight-threatening conditions where systemic treatment with immunosuppressants may be indicated, such as PIC.

Our patient was highly sensitive to visual symptoms in her 'only' eye, but similar changes may often be missed by patients (e.g. if occurring in the worse-seeing eye). For the clinician, the changes in PIC may be subtle and may be missed on clinical examination or nonquantitative assessment of imaging. In our dedicated PIC clinic, all patients have longitudinally tracked retinal thickness maps facilitating detection of new lesions even in asymptomatic patients, guiding treatment decisions and quantifying treatment response. This case highlights how changes on these maps can easily be visualised, providing an objective correlate to the patient's symptoms and enabling confidence in treatment. The use of these thickness maps enables rapid screening for new or changing lesions which can then be analysed in more detail on the 'b mode' SD-OCT scans; thickness maps therefore augment rather than replace the 'b scans'.

This technique depends on accurate segmentation of the SD-OCT images, which can be readily checked prior to interpretation of maps. Extensive chorioretinal scarring may cause failure of automated segmentation but can be easily overcome by applying manual segmentation. Decentration of the macular grid will also affect individual subfield thickness measurements, so all 'followup' images should be acquired or interpreted against a designated reference scan [6]. It should be noted that the technique is not specific to the Heyex ${ }^{\text {tm }}$ software. Most OCT manufacturers provide retinal thickness maps as standard, and therefore, this application should be widely available for monitoring patients with PIC or other white dot syndromes. Devices do, however, vary in their resolution and in the accuracy of their registration between baseline and follow-up scans. This may affect the reliability of detecting change over time, particularly the subtle but functionally significant changes seen in many white dot syndromes.

In PIC, recurring inflammatory lesions occurring close to fixation may lead to a significant loss of vision and immunomodulatory treatment is advised. Additionally, the clinician should be alert to the development of inflammatory $\mathrm{CNV}$, which is a relatively common complication of PIC, and should be confirmed by retinal angiography and timely treatment initiated including the 


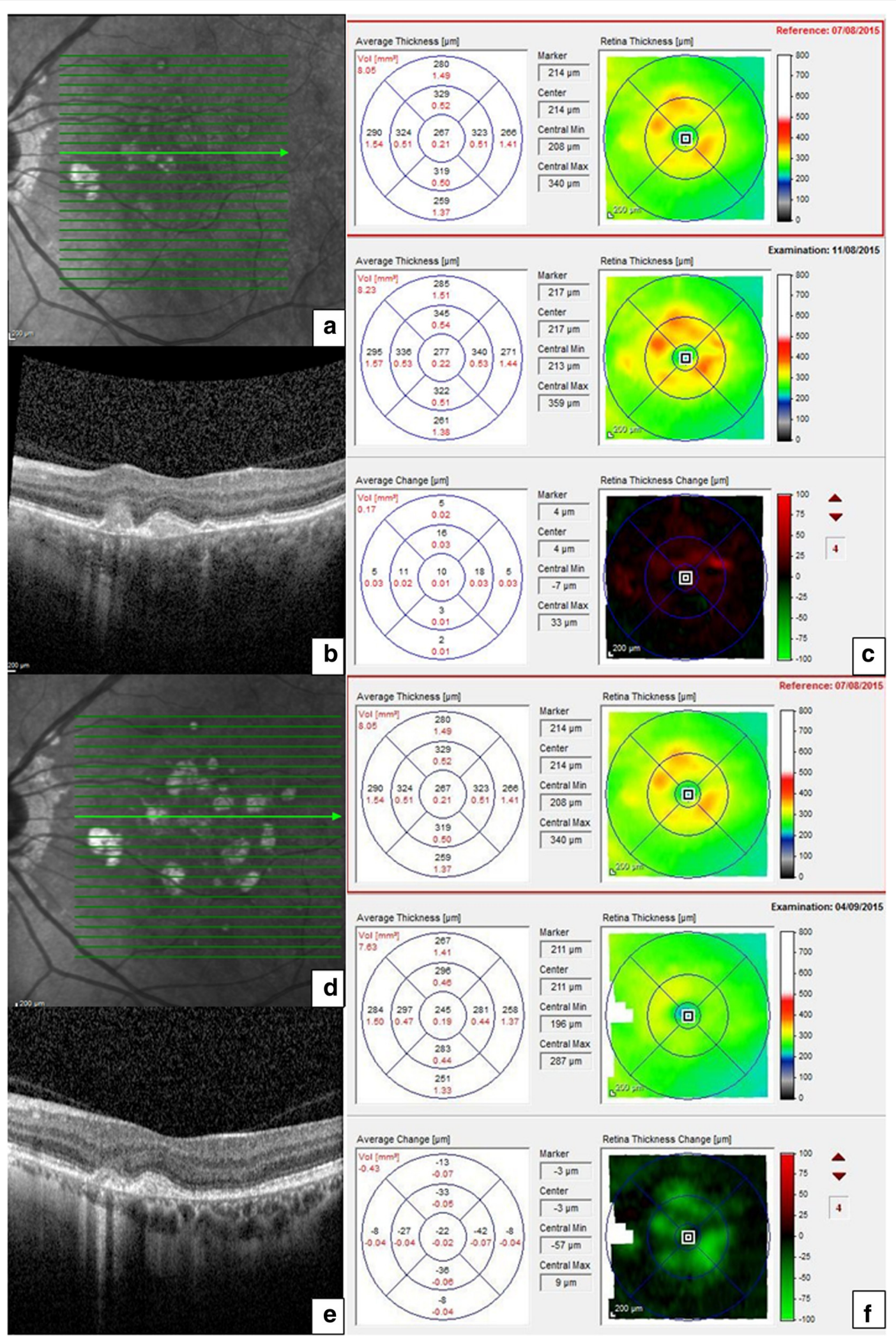

Fig. 1 (See legend on next page.) 
(See figure on previous page.)

Fig. 1 Comparative retinal thickness maps and SD-OCT images from an active and subsequent quiescent phase of punctate inner choroidopathy lesions in the patient's left eye. SD-OCT during a symptomatic flare-up showing focal disruption of the RPE and ellipsoid zone associated with a dome-shaped hyperreflective area $(\mathbf{a}, \mathbf{b})$ and corresponding retinal thickness maps showing an increase in retinal thickness in the form of increase in the number, size and intensity of 'hot spots' compared to the reference with quantitative analysis of average change (c) in different subfields of the macular grid. SD-OCT was repeated 23 days after intravitreal triamcinolone for the above episode showing involution of the active lesion (d, e) and resolution of the hot spots on the corresponding retinal thickness maps compared to the same reference scan, together with quantitative analysis of the average change in retinal thickness ( $\mathbf{f}$ )

use of anti-vascular endothelial growth factor (antiVEGF) therapy [7]. There is little data to support the use of one immunosuppressant over another in PIC, but Neri has reported on the combination of high-dose corticosteroid in combination with mycophenolate mofetil (MMF) for the treatment of refractory inflammatory $\mathrm{CNV}$, including five eyes with PIC. In this series, the regimen of three pulses of $1 \mathrm{~g}$ intravenous methylprednisolone, oral prednisolone (starting at $1 \mathrm{mg} / \mathrm{kg} /$ day) and MMF (1 g twice daily) was well tolerated and led to stabilisation or improvement in visual acuity and stabilisation or reduction of lesion size in all lesions [8]. SDOCT is already a valued tool in the objective assessment of macular oedema in uveitis and is increasingly finding new applications [9]. In these instances, the use of retinal thickness maps is helpful to ascertain lesion activity. In conclusion, retinal thickness map tracking provides a sensitive, reliable, objective way of monitoring PIC and, in this era of multimodal imaging, it may prove a useful adjunct in managing other conditions in the spectrum of white dot syndromes.

\footnotetext{
Abbreviations

PIC: punctate inner choroidopathy; CNV: choroidal neovascularisation; SDOCT: spectral domain optical coherence tomography; FAF: fundus autofluorescence.
}

\section{Competing interests}

The authors declare that they have no competing interests.

\section{Authors' contributions}

SM drafted the manuscript and was involved in patient care. PK was involved in data interpretation and critical revision of the manuscript. $A D$ provided the clinical consultation for the patient; was involved in the data analysis, writing and editing of the manuscript; and provided the overall supervision. All authors read and approved the final manuscript.

\section{Acknowledgements}

Alastair Denniston had full access to all the data in the study and takes responsibility for the integrity of the data and the accuracy of the data analysis.

\section{Author details}

'Centre for Rare Diseases, University Hospitals Birmingham NHS Foundation Trust, Birmingham, UK. ${ }^{2}$ Ophthalmology Department, University Hospitals Birmingham NHS Foundation Trust, Birmingham, UK. ${ }^{3} \mathrm{NIHR}$ Biomedical Research Centre for Ophthalmology, Moorfields Eye Hospital NHS Foundation Trust and UCL Institute of Ophthalmology, London, UK. ${ }^{4}$ Centre for Translational Inflammation Research, Institute of Inflammation and Ageing, College of Medical and Dental Sciences, University of Birmingham, Birmingham, UK.
Received: 7 November 2015 Accepted: 22 February 2016

Published online: 10 March 2016

\section{References}

1. Watzke RC, Packer AJ, Folk JC, Benson WE, Burgess D, Ober RR (1984) Punctate inner choroidopathy. Am J Ophthalmol 98(5):572-584

2. Gerstenblith AT, Thorne JE, Sobrin L, Do DV, Shah SM, Foster CS, Jabs DA, Nguyen QD (2007) Punctate inner choroidopathy: a survey analysis of 77 persons. Ophthalmology 114(6):1201-1204

3. Zhang X, Zuo C, Li M, Chen H, Huang S, Wen F (2013) Spectral-domain optical coherence tomographic findings at each stage of punctate inner choroidopathy. Ophthalmology 120(12):2678-2683

4. Zarranz-Ventura J, Sim DA, Keane PA, Patel PJ, Westcott MC, Lee RW, Tufail A, Pavesio CE (2014) Characterization of punctate inner choroidopathy using enhanced depth imaging optical coherence tomography. Ophthalmology 121(9):1790-1797

5. Li M, Zhang X, Wen F (2015) The fundus autofluorescence spectrum of punctate inner choroidopathy. J Ophthalmol 2015:202097

6. Pak JW, Narkar A, Gangaputra S, Klein R, Klein B, Meuer S, Huang Y, Danis RP (2013) Effect of optical coherence tomography scan decentration on macular center subfield thickness measurements. Invest Ophthalmol Vis Sci 54(7):4512-4518

7. Amer R, Lois N (2011) Punctate inner choroidopathy. Surv Ophthalmol 56(1): $36-53$

8. Neri P, Manoni M, Fortuna C, Lettieri M, Mariotti C, Giovannini A (2010) Association of systemic steroids and mycophenolate mofetil as rescue therapy for uveitic choroidal neovascularization unresponsive to the traditional immunosuppressants: interventional case series. Int Ophthalmol 30(5):583-590

9. Onal S, Tugal-Tutkun I, Neri P, P Herbort C (2014) Optical coherence tomography imaging in uveitis. Int Ophthalmol 34(2):401-435

\section{Submit your manuscript to a SpringerOpen ${ }^{\circ}$ journal and benefit from:}

- Convenient online submission

- Rigorous peer review

- Immediate publication on acceptance

- Open access: articles freely available online

- High visibility within the field

- Retaining the copyright to your article

Submit your next manuscript at springeropen.com 